\title{
A Refined Concept on Emergency Evacuation by Lifts
}

\author{
KELVIN H.L. WONG, M.C. HUI, D.G. GUO, and M.C. LUO \\ Arup Fire \\ Ove Arup \& Partners Hong Kong Ltd \\ Level 5, Festival Walk \\ Kowloon Tong, Hong Kong, SAR
}

\begin{abstract}
A refined concept on emergency total evacuation by lifts has been proposed in this paper. The proposed evacuation strategy consists of combining stair evacuation from a group of occupied floors to a refuge floor followed by lift evacuation from the refuge floor to street level. The provisions of lift shaft pressurization or water entry protection in lift shaft can be eliminated since shuttle lifts with blind shafts without any openings on typical floors are used as the evacuation lift. The possible risk of fire and smoke affecting the occupants waiting in the lift lobbies can be solved completely since the lift pick up floors are located on the refuge floor levels, which are designed to be a temporary place of safety for occupants' refuge. This refined emergency lift evacuation strategy has been studied in a proposed super-high rise building. The traditional total building evacuation using stairs and the proposed alternative evacuation strategy have been simulated using a 3-D evacuation software STEPS to demonstrate the evacuation efficiency. The results show that the total building evacuation time can be shortened significantly by adopting the refined concept, and such concept can be put into practical usage without significant violation to existing conventional stair evacuation strategy and without additional investment in evacuation safety provisions.
\end{abstract}

KEYWORDS: egress, lift, high rise building, modelling, emergency evacuation

\section{INTRODUCTION}

During the last few decades, extensive research has been made on the feasibility of using lift as a means of evacuation in case of emergency. Most of the problems have been addressed thoroughly and corresponding solutions have been proposed. Although most of the predicted problems can be solved from a technical perspective, it is generally accepted by the society that due to the complex nature of lift operation and the perceived adverse effect by smoke, water and heat on lifts, it is better to disregard the lift and follow the traditional use of stair as the only means for emergency evacuation to reach safety.

However, the traditional egress provisions of buildings are primarily designed for fire scenarios in which zoned or phased evacuation [1] for high rise buildings is suggested and considered effective to cater for most of the fire scenarios. In recent years, the community becomes more concerned about the possibility of terrorism such as bomb threat and NBC (Nuclear, Biological and Chemical) attack. Traditional provisions in terms of compartmentation and egress are not sufficient to handle these new situations. All the concerned parties are discussing at length how to ensure that high rise evacuation will happen effectively and in a timely manner [2]. In addition, as the industry and the society are still interested to drive towards bigger, taller and more prestigious development despite the event of September 11, 2001, it is expected that solutions on efficient evacuation of tall buildings are required to enhance life safety in tall and 
complex developments [3]. In some cities, the provision of designated refuge floor is required in high rise buildings [4]. Refuge floors can act as a temporary place of safety for a short rest before occupants continue their journey in stairs evacuation, but occupants are still required to have a means to leave the building. Without imposing a height limitation or providing more and wider stairs, lift evacuation can be an important part of the solutions to the efficient evacuation of tall buildings.

Lifts are not a mere convenience in normal service; they have become an integral component in the building design, especially on the issue of accessibility. It is not realistic to demand occupants in high rise and super-high rise buildings to use stairs, especially when safety procedures demand a quick, efficient and safe means of egress. Lifts are also a means of evacuating mobility impaired occupants [5] since it is not realistic to expect the fire services personnel to carry people to safety via what may be hundreds of flight of stairs.

From a performance point of view, lift is an efficient means of evacuation during emergencies. When lifts are used in conjunction with stairs, it could reduce the amount of time for total building evacuation significantly [6]. Interviews have shown that it took an hour to descend downwards from 91/F of World Trade Centre to street level using stairs [7]. Given that this was not at the peak hour, additional queuing time would need to be added. Lifts could be used to evacuate occupants with disabilities who cannot descend stairs without assistance. Even for people without disabilities, descending many flights of stairs is an onerous task in high rise buildings. Furthermore, people evacuating by stairs could be exposed to other kinds of dangers such as tiredness, becoming dizzy, slipping on surfaces or experiencing fatigue, especially on those newly constructed super-high rise buildings close to $500 \mathrm{~m}$ high in the Asia-Pacific region. A reduced number of occupants using stairs can also help to free up space in the stairs for more efficient fire fighting person's access on upper floors [8]. Accordingly, despite the perceived potential safety risk, lift evacuation strategies have been established in a few special structures such as the airport control tower [9] with restricted access, and the British Telecom Tower [10] in London and the Stratosphere Tower [11] in Las Vegas that are open to the general public.

\section{ISSUES TO BE ADDRESSED ON USING LIFTS FOR EVACUATION}

Although lifts have been proved to provide one of the safest forms of transportation in normal operation, there are some concerns about using lifts for emergency evacuation. The problems in using lift as a means of evacuation in fires have been listed in some of the early editions of the NFPA Life Safety Code, but these have been taken out since the 1981 edition. In general, the problems associated with using lifts in evacuation can be divided into three main areas: reliability of the lift system, protection of passengers, and human's perception in using lifts during emergencies.

The lifts, when operating under emergency situations, need to be at least as reliable as that in normal usage. With regular maintenance and good management, "active" systems like lifts can be regarded as reliable as "passive" systems, such as fire rated barriers. Nevertheless, in case of fire emergencies, the reliability of lift systems could be reduced by the attack of heat and water.

Like all other floor penetrations, lift shafts of great length passing through the building are one of the routes for fire and smoke to spread. The MGM Grand Hotel fire in Las Vegas in November 1980 showed that smoke spread to each level of the high rise floors through lift shafts, and the rooms located on the higher levels that were closer to 
the lift lobbies had a larger number of fatalities [12]. Stack effect on air movement is caused by natural buoyancy or by combustion gases of substantially different temperatures from the ambient surrounding. The high-speed movement of a lift through its shaft causes a piston effect in the shaft, in which a negative pressure is induced behind the lift car when it moves [13]. The pressure difference will further enhance air and then smoke or fire propagation through the gap in the lift lobby door opening to the lift shaft [14]. Hence, beside smoke and fire spread onto different floors, both the occupants inside the lift cars and lift electronic equipment will be under the threat of smoke and heat.

There may also be cases where heat on the fire floor could activate call buttons bringing lift cars to the fire floor, in which both passengers and fire fighters can be endangered. There is also a risk of power supply failure during a fire when the power supply or lift machine room is under the threat of fire. This can result in inoperative lifts, and if it happens during the evacuation period, occupants will get caught in the lifts.

Water is a common agent for fire suppression and fire fighting. During a fire situation it is conceivable that considerable quantities of water may be present at the lift shaft landings. The automatic sprinkler system or fire hydrants used in fire fighting can discharge over a thousand litres of water per minute on fire floors for just a single riser [15]. That water must have a means to flow out. Lift shafts, pipe ducts and staircases are possible paths for doing that. Water in the lift shaft may short the delicate electrical devices in the lift and the mains power of the lift system.

Passengers waiting for and taking the lifts need to be protected from fire and smoke, especially those occupants waiting in the lift lobby for the lift cars. The waiting time can be up to a few minutes, depending on the lift system design, which can be long enough for smoke and fire to spread from the area of fire origin to the lift lobby.

There is also a potential hazard of using a means of evacuation radically different from the traditional ones. Throughout most of the world, there have been warning signs next to the lift and educational campaigns to advise people not to use lifts in fire situation. The potential danger of using lifts during fire is well known and long accepted by both laymen and experts. Occupants may not have confidence that the lifts will operate as planned, and may resist and even refuse to take the evacuation lifts which are perceived to be unreliable and dangerous, resulting in confusion and long pre-movement time.

\section{REVIEW OF CURRENT CONCEPT ON USING LIFTS FOR EVACUATION}

In general, the current lift evacuation strategy is a dedicated lift operated in a downward collective mode. The lift is sent to the highest floor or other designated floor on the first trip, and in the subsequent trips only responds to calls from the second highest floor or other designated floors once no more calls are received from the previous designated floors. But due to the aforementioned problems, different approaches and solutions on emergency lift evacuation have been proposed in the literature and real buildings to address each problem specifically. NIST [16] has carried out extensive studies and experimental investigation on the use of lift for evacuation in buildings. Those recommendations plus the most recent development are discussed below.

Lift shafts need to be protected by dedicated smoke management systems to maintain a positive gauge pressure in relation to adjacent spaces. The system must be effective even during the movement of lift cars in the evacuation period. Lift shaft pressurization systems can prevent smoke spread from the fire floor to the lift shafts, however an 
overpressure may cause the lift door jammed in the open position. Experiments showed that the pressure inside lift shafts varied significantly when lift doors were opened and failed to create a positive pressure in a tall building [17]. To overcome such drawback, multiple injection points along the lift shafts are required, resulting in more investment in space and propeller fans. An alternative is to have the lift shafts open to the outside [11]; this can provide a good means of venting the smoke out. This alternative solution is however not feasible if the lifts are separated into zones and located in the core of buildings. The lifts in such case must have fire resistant lift lobbies to separate them from other parts of the building, otherwise automatic fire shutters would need to be provided in front of the lift doors; the latter method could only be used on floors where lifts are not required for evacuation.

The lift lobbies should be designed to prevent water entering the lift shafts. This can be done by directing the water away to staircases, sloping floors in the lobbies away from the lift, or providing drains immediately in front of the lift doors to remove water. The amount of water discharged and the required drainage capacity can be estimated from the fire services provisions. An alternative approach to handle water spillage to lift shafts is to provide some degree of water proof protection to all electrical components in the lifts and lift shafts. Lifts that can operate in an outdoor environment can be taken as a reference; but how the lift components are to be tested after the installation on site for water resistance is a problem. Without periodical testing, components could degrade or damage after years of use [18].

The lift lobbies should be a protected space for passengers waiting for lifts. There is a need for lift lobbies to be pressurized such that smoke is not likely to spread into lift lobbies and affect occupants waiting for lifts. Occupants waiting for lifts may need to communicate with the person who controls the lift during emergency, and the controller in turn may also need to have communication with the passengers.

Special consideration is required on the protection of lift machine rooms and the lift power supply system that are key elements in the building to ensure a smooth operation of lifts in evacuation. Gas flooding instead of water suppression system should be used, and the lift machine rooms should be elevated to prevent the inflow of water from flooding outside. Multiple mains connections and backup power supply are necessary to ensure a continuous power supply [19].

Different strategies have been proposed to initiate lift evacuation using a life safety system approach [20]. These strategies involved the control of lifts towards different prioritised floors, and required occupants on a few floors near the fire floor to use stairs to descend to lower floors, before taking the lifts. These strategies are comprehensive but will involve many management and implementation issues, since the evacuation strategy will be different for different scenarios.

An early study [21] has been conducted on the combined stair and lift evacuation in a hypothetical building. Occupants were proposed in that study to use stairs for the first ten minutes of total evacuation followed by using lifts after ten minutes when the responding fire services checked and approved the lifts. Hand calculations based on empirical equations were used to estimate the evacuation time and occupants who refused to take the evacuation lifts and insisted to use stairs were not considered. Other similar studies on evacuation were focused on the preferred minimum stair width to assist the choice of stair widths stipulated in standards and codes [22]. 


\section{A REFINED CONCEPT ON USING LIFTS FOR EVACUATION}

In order to address the major problems in lift evacuation discussed before (i.e., smoke spread into lift shafts, water spillage, fire hazard to occupants in lobbies), a refined concept of lift evacuation strategy has been proposed. The performance of the proposed evacuation strategy has been studied using a high rise building as an example to demonstrate the effectiveness of the refined concept.

The refined evacuation strategy concept consists of combining stair evacuation from a group of occupied floors to a refuge floor followed by lift evacuation from the refuge floor to street level. In case of an emergency where a total building evacuation is required, occupants on each floor will evacuate through the stairs to the refuge floors first, where the occupants can choose to travel down to the street level by using shuttle lifts or stairs. It is recommended that both stairs and lifts can be used to evacuate occupants from the refuge floors, and lifts would be the primary means in evacuation. In the proposed refined concept, lift lobbies on each normally occupied floor will not be used as a refuge area for occupants.

Refuge floors are provided in the refined concept as a temporary place of safety for occupants to take a rest and wait for the evacuation lifts during emergency evacuation. It is a statutory requirement in some places, such as Mainland China [23], Hong Kong [24] and Macau [25], to provide refuge floors in tall buildings. Refuge floors are seen to act as a safe place for a short rest before people continue to escape downwards or change to another stair when occupants encounter smoke, fire or obstruction in the original staircase. The size of refuge floors is designed to cater for all occupants above the refuge floor with prescribed stair discharge capacity. The general requirements of refuge floors are to have adequate height, lighting, ventilation, signage, free from obstruction, and complete with fire rated construction to separate the building. Refuge floors are important components in this refined lift evacuation concept. The requirements of refuge floor in the refined concept will be the same, except that shuttle lifts are able to pick up passengers there. Since refuge floors are originally designed to be a temporary place of safety for the staging of building occupants during the phased evacuation, it is safe for occupants to take rest and stay there to wait for the evacuation lifts. The risk of fire and smoke affecting the occupants waiting in the normal lift lobbies in traditional lift evacuation strategy can thus be eliminated.

In the refined concept, shuttle lifts are used as the evacuation lifts. Local lifts within each zone will not be used to pick up passengers between floors. The use of shuttle lifts can eliminate the complicated control and management to pick up occupants on different levels. These shuttle lifts only travel between the refuge floors and the street level. The shuttle lift shafts are blind shafts where there are no openings on typical floors, therefore the provisions of a practically complicated lift shaft pressurization system and lift lobby water entry protection can be eliminated for these shafts completely, since it is impossible for smoke and water on the fire floors to affect the lift shaft if there are no openings. In order to provide a standard for the evacuation lift design, it is suggested that the shuttle lifts for evacuation should be designed according to the standard for fireman's lift detailed in the respective country's standards and regulations [26].

Changes to the policy and people's perception in using lift for evacuation are possible. Actually, most individuals only know that they are not supposed to use lifts in case of fire, but they do not know exactly why they cannot use them [27]. Since these shuttle lifts are the lifts that occupants use everyday to gain access to the building, they have more 
confidence in the lifts' reliability and operation procedures. In addition, after descending many flights of stairs, most occupants would like to use lifts, when they have reached refuge floors, for the rest of their journey. Analysis of first person accounts also showed that some $24 \%$ of WTC 2 occupants were willing to choose lifts, in their own accord, at some point in the time during their evacuation [28]. This statistical data demonstrated that occupants in high rise buildings could be willing and prepared to use lifts in evacuation in case of emergencies [29]. With proper education and periodical drill exercises, occupants' confidence in using lifts for evacuation can be established.

Modern communication technology such as mobile phones, wireless e-mail devices and pagers were found to have been used by the evacuating occupants frequently as a means of gathering information about the situation unfolding around them during emergencies [28]. In order to relieve the occupants' concern, staff is required to be located on the refuge floors and in each shuttle lift used for evacuation to provide information and control the lift movement. Occupants would be more comfortable when they find staff helping them nearby and willing to be in the same lift travelling with them. A command control centre is also required to coordinate and provide information throughout the evacuation process through the building public address system. The command centre, staff inside each shuttle lift and the building public address/CCTV system together form a comprehensive information release and communication architecture.

\section{COMPARISON OF THE REFINED CONCEPT WITH TRADITIONAL METHOD OF STAIR EVACUATION}

\section{Evacuation Simulation}

Hand calculations based on empirical equations have been used in the early days [21] to establish the combined lift and stair evacuation time. With the advancement of computer technologies, computer simulation becomes a modern tool to quantify the benefit of using lifts in evacuation, and has been used by NIST in the review work in the early 90's for four GSA buildings in the USA [30]. However, most of the previous studies on lift evacuation efficiency were based on empirical equations with the assumption that occupants act like ball bearings rather than an aggregate of individuals. Given the availability of models which include greater behavioural details [31], an evacuation simulation software STEPS (Simulation of Transient Evacuation and Pedestrian movementS), with the capacity to define each individual's human factors, has been used in the characterization of the refined lift evacuation strategy to give more realistic results. STEPS is designed to simulate how people move in both normal and evacuation situations within complex building structures [32]. Other software is available for lift evacuation modelling [33], but STEPS can model the lift and stair evacuation simultaneously with visualization and collection of detailed data.

The calculation algorithms in the STEPS model are based on a grid system, where walls etc. are put in as obstructions. People are then added to the system in available predefined cells. In the model, each person calculates a score for every exit on the current plane based upon four cumulative criteria: the shortest distance to an exit, familiarity with an exit, crowding around an exit and the service rate of each exit. The total score is calculated for each person on every time step with the consideration of distance to the exit, walking speed, number of persons queuing at the exit, exit flow rate, number of persons in front of the calculated ones, number of persons reaching the exit, occupants' patience level, and occupants queuing and walking characteristics. 
Three interconnecting components in the model are considered: the plane and path network, the description of the human characteristics, and the movement of the people within the system. The algorithm for a person to select the travel path is based on a combination of decision and network-based models. Planes that represent the actual floor space consist of a grid configuration on which people can walk, the spacing of which is dependant on the maximum specified population density. Alternatively, predefined paths or planes are used to represent stairways, upon which deviations of the walking directions are not possible until another path or plane is reached.

The specification of the model population consists of describing people types, body dimensions and their associated walking speeds. The maximum walking speed and flow rate values reported in the SFPE Handbook [35,36] have been adopted in the model. Parameters for occupants' familiarity and patience are based on the default values in the software.

The software is able to show the evacuation process in 3D graphical animation, and users can rotate the model and use the zoom function to move in and out of the animation for a more detailed inspection. Some of the simulation snapshots of a super-high rise building during evacuation are shown in Fig. 1.

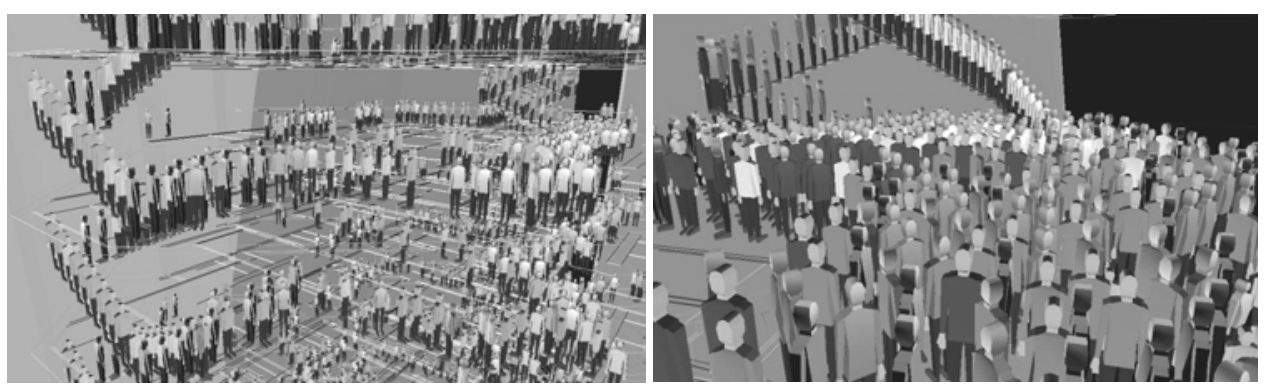

Fig. 1. Simulation snapshot on typical floors (left) and refuge floor (right).

The accuracy of the software was verified [36] by comparing its results with two hand calculation examples demonstrated in NFPA 130 [37] Appendix C. The STEPS results of both examples give longer and more conservative evacuation times than the figures obtained from NFPA 130 hand calculations (longer by $0.9 \%$ to $11.4 \%$ ). In contrast to NFPA hand calculations, the STEPS model simulates an uneven population distribution in using stairs during evacuations, which leads to a more realistic result.

\section{Simulation Results}

A total building evacuation of a $500 \mathrm{~m}, 100$ storeys super-high rise office building has been simulated. The number of occupants inside the building was estimated according to the prescriptive value of $9.3 \mathrm{~m}^{2} /$ person [38]. This value is close to most of the prescriptive occupant load densities for office space throughout the world. The total number of occupants in the evacuation is approximately 21,000. Three stairs, each of $1200 \mathrm{~mm}$ in width, have been provided according to the IBC [39]. The building has four refuge floors, each serving a maximum of 24 storeys, used as the staging area during lift evacuation and there are 14 shuttle lifts concentrated within the building core travelling between the refuge floors and the street level as evacuation lifts. 
The total building evacuation has been simulated in a way that all the occupants start the evacuation at the same time. This is the worst scenario as far as stair usage is concerned. Two scenarios, (a) traditional evacuation using stairs only, and (b) the refined lift evacuation strategy of using lifts and stairs together, have been simulated. The percentage of occupants using stairs and lifts on the refuge floors for Scenario (b) is determined by the software based on queuing time and patience level. The only parameter imposed in the model was the time restricting the usage of stairs or lifts on refuge floors. A number of trials have been simulated for Scenario (b) until the times for the last person from stairs and lifts to reach ground floor are the same in the model, which is the case that the discharge capacities of both stairs and lifts are fully utilized. The cumulative percentage and number of occupants evacuated from the building have been plotted against time in Fig. 2. For the case of any undetermined human factors, such as occupants hesitating and refusing to take the evacuation lifts and insisting to use stairs for evacuation, the simulated evacuation times will be bounded by the two cumulative percentage curves on the left of Fig. 2.

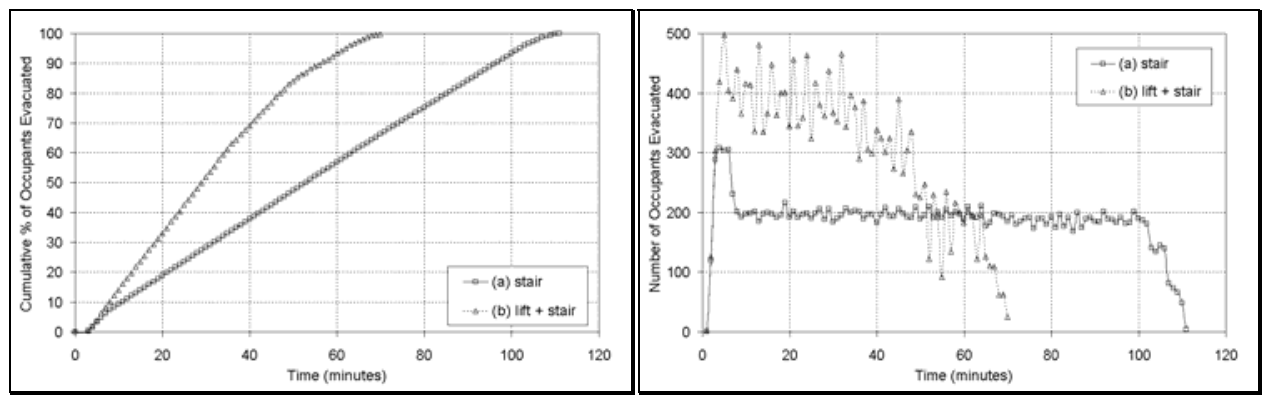

Fig. 2. Comparison of evacuation time: cumulative percentage (left) and number of occupants (right).

The slope of the cumulative percentage curves on the left of Fig. 2 is the occupant discharge rate. Since Scenario (b) uses both stairs and lifts to discharge occupants, it is obvious that it has a steeper slope than Scenario (a). The slope of Scenario (a) is generally constant throughout the evacuation period. It means that the capacity of the stairs has been used evenly and completely. In order to shorten the evacuation time in Scenario (a), either the total stair width is increased or the number of occupants is decreased. This result is also reflected on the right of Fig. 2, which shows the number of occupants evacuated at each minute in Scenario (b) is nearly double that in Scenario (a) at the early stages when the lift capacity was fully utilized. The observed change of slope at around 50 minutes in the curve for Scenario (b) indicates that not all evacuation lifts are fully utilized at that time. On one of the refuge floors, Refuge B, most of the occupants have been evacuated after 50 minutes as shown on the right of Fig. 3. The evacuation lifts on that refuge floor no longer carry passengers, after 50 minutes, to the street level. Therefore the rate of occupants discharging outside the building decreased from that time. Encouraging more occupants to take the evacuation lifts instead of using stairs on that refuge floor can increase and maintain the discharge rate.

When comparing the total building evacuation times, it can be seen that using lifts and stairs in the refined evacuation concept can reduce the evacuation time by $36 \%$ (see Table 1). Besides the total evacuation time, the time for a certain percentage of occupants who evacuated from the building can be another indicator to quantify the evacuation efficiency. In most cases, the total evacuation time is dominated by a few occupants who 
leave the building very late. From Table 1, it is apparent that the evacuation time can be shortened by up to $58 \%$ if a combined lift and stair evacuation strategy is adopted. This shows that the refined concept of lift evacuation is more effective in evacuating a large number of occupants at the early stage of evacuation.

Table 1. Comparison on percentage of occupants evacuated.

\begin{tabular}{|c|c|c|c|}
\hline Percentage evacuated & (a) stair & (b) lift + stair & Difference \\
\hline $25 \%$ & 26 mins & 11 mins & $-58 \%$ \\
\hline $50 \%$ & 53 mins & 25 mins & $-53 \%$ \\
\hline $75 \%$ & 80 mins & 41 mins & $-49 \%$ \\
\hline $90 \%$ & 96 mins & 53 mins & $-45 \%$ \\
\hline $100 \%$ & 110 mins & 70 mins & $-36 \%$ \\
\hline
\end{tabular}

The number of occupants on two of the refuge floors has also been plotted to investigate the changes in occupant numbers at different times. Two refuge floors, one at the highest level (Refuge A) and one at the mid level (Refuge B), have been selected for investigation. Scenario (a) and Scenario (b) for these two cases have been plotted in Fig. 3. The percentage of occupants on the refuge floor is calculated by counting the number of occupants on the refuge floor at any instant over the total number of occupants that should be discharged onto this refuge floor.
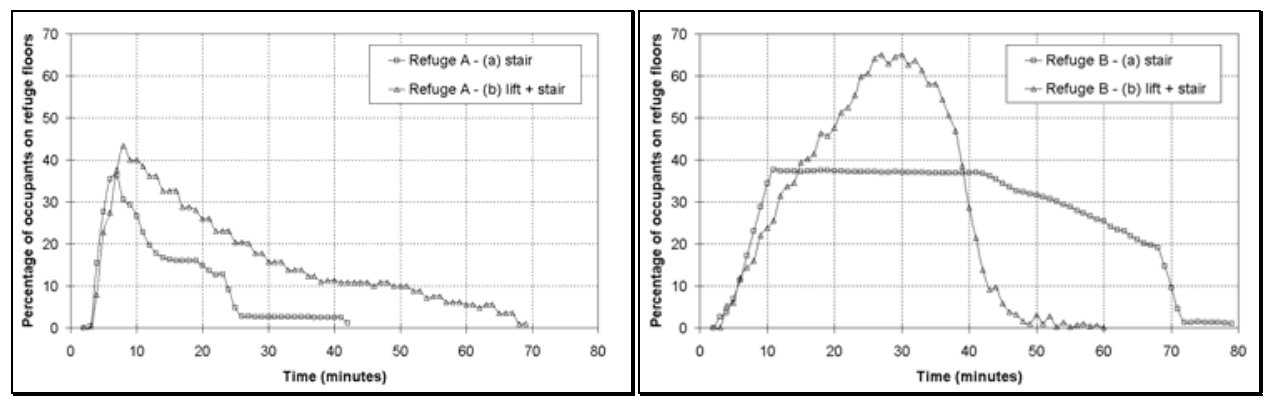

Fig. 3. Comparison of occupant numbers on refuge floors.

The plateau on the curves of Scenario (a) indicates that the staircases below the refuge floors are fully occupied, occupants on the refuge floors need to wait until occupants on the lower floors are discharged and the space inside the staircases is freed up. In a high rise building total evacuation, most of the occupants are still needed to wait on the refuge floors, which is the same as using lifts in evacuation. This implies that the psychological state for occupants waiting on the refuge floors, like anxiety, is almost the same as that in the stair evacuation. With designated staff in each shuttle lift and on each refuge floor, instant and direct announcements can be made to the occupants to enhance communication. The peak percentage of occupants on the refuge floors for Scenario (b) is higher than Scenario (a), but is still within the limit (100\%) since refuge floors are designed to cater for all the occupants above the refuge floors to stay there.

\section{CONCLUSIONS}

A refined concept on emergency evacuation by lifts has been proposed in this paper. With the combination of stair evacuation and lift evacuation, the total building evacuation time can be reduced significantly without complicated implementation procedures and violation of traditional stair evacuation strategy. The use of shuttle lifts as evacuation lifts 
can eliminate the provisions of lift shaft pressurization and water entry protection in the lift shafts since there will be no shaft opening on typical floors. The selection of refuge floors as lift pick up floors can eliminate the hazard of fire and smoke affecting occupants waiting for lifts since refuge floors are designed to be a temporary place of safety for occupants' refuge. Computational evacuation models have been used to simulate the total building evacuation of a super-high rise building. It is shown that the refined concept of lift evacuation has advantages over stair evacuation in terms of total building evacuation time and percentage of occupants discharged. The refined evacuation concept can reduce the total building evacuation time by $36 \%$. With further input and refinement in the design of shuttle lift capacity and refuge floor locations, the performance of floor clearance time and percentage of occupants on refuge floors can be further improved. This paper has proposed a refined lift evacuation concept that can be put into practical use without significant violation to existing stair evacuation strategy and additional investment in evacuation safety provisions. Further studies will need to be conducted on the use of this refined concept on buildings of different heights, lift capacity and occupant factors such as total number of occupants and degree of ambulance of occupants for sensitivity analyses.

\section{REFERENCES}

[1] Fire Safety Guide No.3 Phased Evacuation from Office Buildings, London District Surveyors Association, London, 1990.

[2] Proulx, G., and Fahy, R.F., "Evacuation of the World Trade Center: What Went Right?," Proceedings of the CIB-CTBUH International Conference on Tall Buildings, Council on Tall Buildings and Urban Habitat, 2003, pp. 27-34.

[3] Russett, S., “Theme: Lifts and Escalators,” The Architects' Journal, April 822, 2003.

[4] Lo, S.M., and Will, B.F., "A View to the Requirement of Designated Refuge Floors in High-rise Buildings in Hong Kong,” Fire Safety Science - Proceedings of the Fifth International Symposium, International Association for Fire Safety Science, 1997, pp.737-745.

[5] BS5588 - 8:1999 Fire Precautions in Design, Construction and Use of Buildings - Part 8; Code of Practice for Means of Escape for Disabled People, British Standards Institution, London, 1999.

[6] Guo, D.G., Wong, K.H.L., Luo, M.C., Kang, L., and Shi B.B., "Lift Evacuation Design of Ultra High Rise Building,” Proceedings of the Fire Conference 2004 - Total Fire Safety Concept, Hong Kong SAR, 2004, pp. 151-158.

[7] Fahy R.F., and Proulx G., "A Comparison of the 1993 and 2001 Evacuations of the World Trade Center," Proceedings of Fire Risk and Hazard Assessment Symposium, Baltimore, MD, 2002, pp. 111-117.

[8] Burns, D.J., “Operation in Tower 1,” The World Trade Centre Bombing: Report and Analysis, United States Fire Administration, Federal Emergency Management Agency, Maryland, 1993, pp. 49-56.

[9] Klote J.H., "Feasibility of Fire Evacuation by Elevators at FAA Control Towers,” National Institute of Standards and Technology Report NISTIR 5445, Gaithersburg, MD, 1994, 104 p. 
[10] Howkins, R., "Lift Modernization BT Tower London,” The Arup Journal 3/2003, pp. 30-31, (2003).

[11] Quiter, J.R., "An Application of Performance Based Concepts at the Stratosphere Tower Las Vegas Nevada," Proceedings of Fire Risk and Hazard Assessment Symposium, Research and Practice: Bridging the Gap, National Fire Protection Research Foundation, 1996, pp. 118-126.

[12] Coakley, D., Greenspun, H., and Gerard, G.C., The Day The MGM Grand Hotel Burned, Lyle Stweart Inc., 1982.

[13] Klote, J.H., "Elevator Piston Effect and the Smoke Problem," Fire Safety Journal, 11, No.2, pp. 227-233, (1986).

[14] Klote, J.H., “Analysis of the Lift Safety Consequences of Smoke Migration Through Elevator Shafts," Atlanta Workshop On the Use of Elevator in Fires and Other Emergencies, American Society of Mechanical Engineer, 2004.

[15] CIBSE Guide D, Transportation Systems in Buildings, Chartered Institution of Building Services Engineers, UK, 2000.

[16] Klote, J.H., Deal, S.P., Levin, B.M., Groner, N.E., and Donoghue, E.A., "Workshop on Elevator Use During Fires," National Institute of Standards and Technology Report NISTIR 4993, Gaithersburg, MD, 1993, 15 p.

[17] Klote, J.H., "Elevators as a Means of Fire Escape," National Institute of Standards and Technology Report NBSIR 82-2507, Gaithersburg, MD, 1982, $32 \mathrm{p}$.

[18] Klote, J.H., Deal, S.P., Donoghue, E.A., Levin, B.M., and Groner, N.E., "Fire Evacuation by Elevators,” Elevator World, 41, No.6, pp. 66-70 \& 72-75 (1993).

[19] Caldwell, J., "Standby Power and Elevator Safety in Fire Emergencies," Elevator World, January, (1996).

[20] Groner, N.E., and Levin, B.M., "Human Factors Considerations in the Potential for Using Elevators in Building Emergency Evacuation Plans,” National Institute of Standards and Technology Report NIST-GCR-92-615, Gaithersburg, MD, 1992, 52 p.

[21] Pauls, J., "Management and Movement of Building Occupants in Emergencies,” Proceedings of Second Conference on Designing to Survive Severe Hazards, IIT Research Institute, Chicago, 1977, pp.103-130.

[22] Pauls, J., "Elevator and Stair for Evacuation: Comparison and Combinations," Atlanta Workshop on the Use of Elevator in Fires and Other Emergencies, American Society of Mechanical Engineers, 2004.

[23] GB 50045-95 Code for Design High-rise Civil Building Fire Protection (2001 ed.), National Standard of the People's Republic of China, Beijing, 2001.

[24] Code of Practice for the Provision of Means of Escape in Case of Fire (1996 ed.), Buildings Department, Hong Kong, 1996.

[25] Regulamento de Segurança contra Incêndios (1995 ed.), Imprensa Oficial de Macau, Macau, 1995. 
[26] Comparison of Worldwide Lift Safety Standards - Fire Fighting Lifts, ISO/TR 16756:2002(E), International Organisation for Standardization, Geneva, Switzerland, 2002.

[27] Proulx, G., "Evacuation by Elevator: Who Goes First?,” Atlanta Workshop on the Use of Elevator in Fires and Other Emergencies, American Society of Mechanical Engineers, 2004.

[28] Proulx, G., Fahy, R.F., and Walker, A., "Analysis of First-person Accounts from Survivors of the World Trade Center Evacuation on September 11, 2001," Research Report No. 178, National Research Council Canada, Ottawa, 2004, 32 p.

[29] Blake, S.J., Gelea, E.R., Westeng, H., and Dixon, A.J.P., "An Analysis of Human Behaviour During the WTC Disaster of 9/11 Based on Published Survivor Accounts," $3^{\text {rd }}$ International Symposium on Human Behaviour in Fire, Belfest, 2004.

[30] Klote, J.H., Alvord, D.M., Levin, B.M., and Groner, N.E., "Feasibility and Design Considerations of Emergency Evacuation by Elevator," National Institute of Standards and Technology, Gaithersburg, MD, NISTR 4870. 1992, $119 \mathrm{p}$.

[31] Gwynne, S., Galer, E.R., Owen, M., Lawrence, P.J., and Filippidis, L., “A Review of the Methodology Used in the Computer Simulation of Evacuation from the Built Environment," Building and Environment, 34, pp. 741749, (1999).

[32] Wong, K.H.L., and Luo, M.C., "Computational Tool in Infrastructure Emergency Total Evacuation Analysis," Lecture Notes in Computer Science, 3495, pp. 536-541, (2005).

[33] Klote, J.H., “A Method for Calculation of Elevator Evacuation Time,” Journal of Fire Protection Engineer, 5, (3), pp.83-95, (1993).

[34] Proulx, G., "Movement of People: The Evacuation Timing," The SFPE Handbook of Fire Protection Engineering ( $3^{\text {rd }}$ ed), DiNenno, P.J. (ed.), National Fire Protection Association, Quincy, MA 02269, 2002, p. 3/347.

[35] Nelson, H.E., and Mowrer, F.W., "Emergency Movement," The SFPE Handbook of Fire Protection Engineering ( $3^{\text {rd }}$ ed), DiNenno, P.J. (ed.), National Fire Protection Association, Quincy, MA 02269, 2002, p. 3/370.

[36] Wall, J.M., and Waterson, N.P., "Predicting Evacuation Time - A Comparison of the STEPS Simulation Approach with NFPA 130," Fire Command Studies.

[37] NFPA 130 Standard for Fixed Guideway Transit and Passenger Rail Systems (2003 ed.), National Fire Protection Association, Quincy, MA 02269, 2003.

[38] NFPA 101 Lift Safety Code (2000 ed.), National Fire Protection Association, Quincy, MA 02269, 2000.

[39] "Means of Escape," International Building Code (2003 ed.), International Code Council, Country Club Hills, Illinois, 2002. 